

\section{CONTENTS}

ABSTRACT

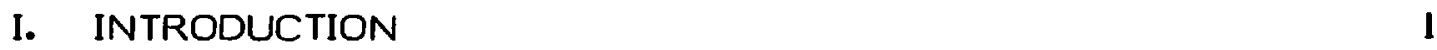

II. CANDIDATE RADIATION DETECTORS 2

A. Radiophotoluminescent Dosimeters 2

B. Thermoluminescent Dosimeters 3

C. Film Badges and Ion Chambers 5

D. Photochemical Dosimeters $\quad 5$

E. Superheated Drop Detectors $\quad 6$

F. Electronic Pocket Dosimeters $\quad 7$

G. Large Electronic Monitors 11

H. Other Radiatjon Detectors $\quad 12$

I. Summary of Dosimeter Characteristics $\quad 12$

$\begin{array}{ll}\text { III. TARGET CHARACTERISTICS } & 15\end{array}$

$\begin{array}{ll}\text { IV. TAMPER-PROOFING } & 17\end{array}$

$\begin{array}{ll}\text { V. OPTIMAL MONITOR APPLICATIONS } & 18\end{array}$

V1. SUMMARY AND RECOMMENDATIONS 20

REFERENCES $\quad 22$

BIBLIOGRAPHY 23 


\section{FIGURE}

Figure 1. Comparative size of some dosimeters

\section{TABLES}

Table 1. Characteristics of Common Batteries $\quad \ldots \ldots \ldots \ldots \ldots \ldots$ II

Table II. Characteristics of Dosimeters $\quad \ldots \ldots \ldots \ldots \ldots \ldots \ldots \ldots \ldots . . . \quad 14$

Table III. Relative Gamma-Ray Intensity Versus Burnup at Fixed Operating Power $\quad \ldots \ldots \ldots \ldots \ldots \ldots \ldots \ldots \ldots$ I5

Table IV. Relative Gamma-Ray Intensity Versus Irradiation ～. . I 16

Table V. Some Specific Application Possibilities $\quad \ldots \ldots \ldots \ldots \ldots \ldots$ 


\title{
RADIATION DETECTORS AS SURVEILLANCE MONITORS FOR IAEA SAFEGUARDS
}

by

\author{
P. E. Fehlau and E. J. Dowdy
}

\begin{abstract}
Radiation detectors used for personnel dosimetry are examined for use under IAEA Safeguards as monitors to confirm the passage or nonpassage (YES/NO) of plutonium-bearir.g nuclear material at barrier penetrations declared closed. In this application where backgrounds are ill defined, no advantage is found for a particular detector type because of intrinsic efficiency. Secondary considerations such as complexity, ease of tamper-proofing, and ease of readout are used to recommend specific detector types for routine monitoring and for data-base measurements. Recommendations are made for applications, data acquisition, and instrument development.
\end{abstract}

\section{INTRODUCTION}

Confirmation of the passage or nonpassage (YES/NO) of nuclear material at barrier penetrations that allow access to safeguarded nuclear material but are declared closed is a form of safeguards surveillance now practiced by the International Atomic Energy Agency (IAEA). The Agency has used Toshiba glass radiation dosimeters enclosed in a metal seal for unattended confirmation and has found compactness, simplicity, low cost, and tamper-indication to be desirable attributes of a YES/NO monitor. The Agency has not gone through a systematic survey of detectors alternative to the Toshiba dosimeters and has requested that such a survey be carried out under the US Program for Technical Assistance to IAEA Safeguards (ISPO Task E.41). This report constitutes a survey of available radiation detectors considered suitable for confirming that fresh or irradiated reactor fuel elements or plutonium-bearing materials have not been taken through a penetration opening during a period of unattended surveillance.

In making the survey, the principal goal was to find radiation detectors that were commercially available or that would be available in the very near future. A secondary interest was directed toward radiation detectors that appeared suitable and seemed to be of such potential value that they would eventually be marketed.

Additional guidance from the Agency during the course of the study suggested that there would be yearly interrogation of the monitor, making reliability of particular 
concern. Also, the yearly interval between inspections makes monitors that require no power or that use host outlets to provide or maintain operating power attractive, although monitors that use self-contained primary lithium batteries seem capable of performing for as long as a year. Further, the Agency has a requirement that the monitor be simple to install, retrieve, and read.

The radiation detectors surveyed will be discussed and evaluated before making a recommendation of deserving systems. Where cost estimates are available, they are for early 1980.

\section{CANDIDATE RADIATION DETECTORS}

\section{A. Radiophotoluminescent Dosimeters}

It might be best to look first at the currently used technique, radiophotoluminescence (RPL), using Toshiba glass dosimeters. The RPL effect is exhibited in a material, criginally nonluminescent under visible or ultraviolet (Uv) illumination, when luminescent centers are formed by exposure to ionizing radiation. Typically, absorption bands in the near uv are formed during irradiation, and illumination with radiation falling in the absorption band results in visible luminenscence proportional (up to perhaps $1000 \mathrm{R}$ ) to the exposure during the irradiation. The process of illumination and measuring the luminescence intensity is the means of reading the RPL dosimeter and it is a nondestructive process, that is, it may be repeated at a later time to give the same result. The time interval between exposure and reading may affect the result through dose build-up or fading. Heating to temperatures near $150^{\circ} \mathrm{C}$ for a few minutes or storage at room temperature for a day is required to reach the maximum luminescent effect. Fading is often just a few percent per year with modern glasses. Heating to higher temperatures causes destruction of the absorption bands, and a nominal $20-$ min period at $400^{\circ} \mathrm{C}$ is adequate to allow re-use of the Toshiba dosimeter. A tactic of subversion by heating can be detected easily using a substance that undergoes a nonreversible change at a calibrated temperature.

RPL dosimeters have been made for use in the gamma-ray dose range of $10 \mathrm{mR}$ to several thousand $R$, independent of dose rate. Use at higher total doses is possible but build-up and fading are more pronounced. Usually, very high dose rates are tolerated well. Garrma-ray energy spectral response is variable by as much as a factor of 10 over the range of $50 \mathrm{keV}$ to $\mathrm{I} \mathrm{MeV}$ but the low energy response can be adjusted with filters to obtain reasonably flat response over this entire energy span. A suitable response to neutrons can be obtained by means of external converters or internal neutron absorbers or scatterers. The fast neutron response is usually rather small bui thermal neutron response can be made quite good.

Precautions in the use of RPL dosimeters include mechanical protection to avoid surface damage and protection from uv light and extreme heat. The uv intensity used in readers is low and damage does not occur, but at the intensity of normal sunlight, the RPL level can be reduced by exposure.

In use, the RPL dosimeter must be packaged for mechanical and uv-light protection and may be exposed for long periods of time. Reading requires careful cleaning of the dosimeter surface and use of a reader. Repeated readings may be carried out to obtain more precise results and the dosimeter may be saved for future reference with only slight RPL intensity loss rate. 
We were unable to find a commercial vendor for RPL dosimeters in the United States. We found users of Toshiba personnel dosimeters who were also unable to obtain additional dosimeters, replacement readers, or reader repairs. A US Army high radiation level dosimetry project team experienced similar difficulty in obtaining Toshiba RPL dosimeters but was able to obtain the dosimeter glass in small quantities from Prof. R. Yakota in Japan. Dr. A. E. Cohen of the Army project at Ft. Monmouth was unable to help us contact Prof. Yakota but did state that Toshiba was interested in resuming production of RPL equipment if the Army project represented a sufficient commercial incentive. We contacted Prof. $Y$. Nishiwaki, 1 ) recently an IAEA staff member now of Toshiba, who commented that the Toshiba dosimeters have been "rather difficult to obtain" but are now in productior. He provided us with the name of $\mathrm{Mr}$. T. Ohmori ${ }^{2}$ ) in Tokyo as the proper contact, but we have had no response from our inquiry. We had a phone call from Mr. T. Aoki ${ }^{3)}$ of Toshiba International in New York City and he offered to send literature, but we had not received any at the time of this report.

Other supp!iers of RPL glass dosimeters to the Army that have been contacted are SEI, Ltd. through Fisher Controls, Ltd.,4) and Frieseke and Hoepfner, Gmbh,5) but neither has responded. An inquiry to R. A. Stephens and Co., Ltd.6) about pocket dosimeters brought some mention of RPL cosimeters and readers in technical literature dated 1964. A further inquiry to R. A. Stephens brought the response that they do supply readers on a contract basis with 500 units minimum. GEC of the UK was the stated glass supplier.

In summary, the RPL dosimeter seems ideal for the surveillance application because it is small, requires no power, can be made tamper-safe easily, and with proper encapsulation and care in reading, can do a suitable job. The drawbacks, in addition to lack of assured supply, are that it can be erased by heat and uv radiation and the small size makes it easily subject to subversion by external shielding during short time intervals when undeclared use is made of a monitored penetration.

\section{B. Thermoluminescent Dosimeters}

Radiothermoluminescent dosimetry materials form metastable states when exposed to ionizing radiation and maintained at or be $w$ the exposure temperature. Reading is carried out by measurement of the integrated intensity of light emitted when the trapped energy in the metastable states is released by an increase in temperature during uniform heating of the thermoluminescent dosimeter (TLD). The reading process includes the necessary annealing step to return the TLD to its intitial state after which it can be re-used, at least in the case of routine ixposures.

A large number of materials display thermoluminescent properties and many of these have been used to some extent in dosimetry. Presently, commercial systems use Lif or $\mathrm{CaF}$ host material containing one or more activators. The activator is in some wa, responsible for effecting the desired performance characteristic and in some cases the activator is known, as in CaF:' $1 \mathrm{n}$, while in other cases the activator is not disclosed. In LiF, for example, the pure crystal exhibits poor sensitivity, but systematic studies of activator performance enhancement resulted in a patented material having not only adequate sensitivity but improved annealing properties. The activator used remains undisclosed.

The physical properties of primary interest in this intended use of TLDs are relative sensitivity, energy response, fading, and susceptibility to spcofing. The first three properties must be considered together in this application. The CaF-based dosimeters are 
hundreds of times more sensitive than the LiF-based dosimeters, but the latter do not have the greatly enhanced low energy photon response of the former and thus, do not need the spectrum tailoring filters used with the former. The relative response of filtered $\mathrm{CaF}_{2}$-based dosimeters is 10 to 30 times more sensitive, but the fading is more serious, being exponential, with $15 \%$ fading in the first two weeks compared to about $5 \%$ per year fading at room temperatures for LiF-based dosimeters. Both fading rates increase under semitropical conditions. There is no large difference in sensitivity for long term exposure applications.

Some secondary differences can become important in this application. Lif has the property that the response is linear with dose up to about $400 \mathrm{R}$, after which its response per unit of dose increases. This characteristic is undesirable in routine dosimetry, but in this application may even be desirable. It is only when the integrated dose exceeds many thousands of $R$ that a problem occurs, and then only for re-use. The LiF dosimeters are desensitized by such high exposures and cannot be re-used. An observed self-dosing effect in $\mathrm{CaF}_{2}$ dosimeters caused by radioactivity in the phosphor itself or by radioactivity from potassium in the glass encapsulation has the effect of increasing the background, making the detection sensitivity lower for this application.

Present practice in personnel monitoring makes use of more than one TLD sensor in each package. The individual components can be used with converters or attenuators to tailor the response for a particular forin of radiation such as beta, gamma, or fast neutron, or a particular energy spectral component. Similarly, with $\mathrm{LiF}$, the $6_{\mathrm{Li}}$ and $7_{\mathrm{Li}}$ fluorides are used in combination to measure thermal neutron exposure. This is done using careful calibration of the gamma response of the neutron absorbing ( ${ }^{6} \mathrm{Li}$ ) natural $L_{i}$ dosimeters and $7_{\text {LiF }}$ dosimeters that have no thermal neutron response. Simultaneous readout of the two TLD types is done and the desired neutron exposure result is obtained by differences.

The useful gamma-ray dose range for TLDs extends from a few $\mathrm{mR}$ to greater than $10^{5} \mathrm{R}$ and the dosimetric property is independent of dose rate up to a limit of $10^{1} \mathrm{l} \mathrm{P} / \mathrm{s}$.

Typical reading instrumerits provide a scheduled sequence of preheating to remove the most variable compronents of light emission, after which a programmed increase in temperature occurs while photometric measurements of the light output of each heated segment are made. Subsequent temperature variation is carefully programmed to return the dosimeter to a reusable state. The method of heating is either by heated plate or passage of heated flowing pure dry nitrogen, and the required time for the entire cycle can be approximately one minute. Some readers are semiautomatic and when manually loaded can process and record results automatically for a number of multichip dosimeters.

Disadvantages of TLDs are similar to those of RPL dosimeters. There is a uv-light sensitivity that can vary with irradiation history and material type, producing an increase in the apparent radiation exposure with $\mathrm{LiF}$, whereas there is a decrease in apparent exposure in the RPL case. The thermal annealing effect is more serious for TLDs than for RPL dosimeters because lower temperatures are used for readout. Heating would be a means of destroying the latent radiation exposure record, but temperatures could be independently measured to expose subversion. Again, a TLD package is not large and could be shielded easily by lead during diversion to reduce the exposure to undetectable levels.

Perhaps the most convenient way of obtaining TLDs is by purchase of a dosimetry service in which the vendor provides the required number of dosimeters on a periodic basis, 
reads the used dosimeters, and provides the results to the customer. The Eberline Corporation7) provides a service in which five identical Lif chips are used for environmental monitoring and for which the present charge is about $10 \mathrm{US} \$$ per year on an annual cycle. Additional initial setup charges are imposed on quantities under 100 dosimeters and minimum bi!ling charges per quarter are imposed. The reading cycle used is said to eliminate fading for use periods up to one year, and effects of light, heat, humidity, and time on response are said to be insignificant. Eberline does not sell complete TLD systems but does sell a TLD reader ( 3500 US\$) that uses a pan heating system for single TLD reading. Eberline also markets accessories for the reader and dosimeters but, as with many vendors, the user must buy the lithium fluoride chips and assemble, calibrate, and establish the uniformity of the final dosimeters himself. Cost of one dosimeter would be on the order of 6 US $\$$ but the means to calibrate and verify performance must also be considered and will add substantially to the cost.

Victoreen ${ }^{8}$ is another well established vendor marketing TLD readers and accessories. The basic reader is also a heated planchet single dosimeter chip reader and the price is about 3800 U5\$. A wide range precision version costs 6000 US\$. The basic reader has been available for some time and has an excellent reputation. Victoreen markets dosimeter chips on a batch quote basis and the same burden is on the user for packaging, calibration, and uniformity check.

Harshaw ${ }^{9)}$ is another supplier of dosimetry systems exclusive of chip holders and is a major producer of the dosimetry materials. In the basic model the reader is in two separate units, one the heater-detector unit and the other an integrating picoammeter. Heating is by planchet and the total cost is about 7250 US\$. A modification of the basic unit can read a two-chip holder by moving the chips through the reader. Harshaw markets more elaborate readers capable of automatically reading quantities of multichip dosimeter cards, but such readers are more useful for periodic routine personnel monitoring. Harshaw sells the LiF dosimetry material in different physical form and the price for chips of LiF in small quantities is about 2 US\$ each. Enhanced or diminished neutron response versions are available at up to twice the cost mentioned. Harshaw does not supply holders but does recommend suppliers of such fixtures to dosimeter chip customers.

In summary, the principal attraction of the TLD is its small size and lack of power requirements or maintenance. The LiF forms are suitable for use on a yearly reading cycle and a commercial service is available that can provide dosimeters, packaging, and reading on a yearly basis. Tamper-indicating enclosures can be provided separately and the cost for the entire monitor should be low enough to allow widespread use.

C. Film Badges and Ion Chambers

Two common personnel dosimeters, one based on photographic film and the other or electrostatic charge measurement, are considered as not acceptable candidates for this application. Charge measurement by ion chamber electrometers is limited by leakage, which is as large as $2 \%$ per day in a good ion chamber. Thus, annual reading is impractical. Film has other drawbacks. It is becoming more expensive, is not reusable, and suffers from blackening by exposure to light, heat above $60^{\circ} \mathrm{C}$, pressure and chemicals. The time and effort required to obtain and read the results are greater than other methods with no increase in utility for this application. Finally, in long term monitoring the fading of film can be induced by exposure to moisture and heat. 
Photochemical dosimetry is possible but, in general, the method is not a practical one for personnel or environmental monitoring. One type of chemical dosimeter is applicable to "YES/NO" monitoring in a lirnited sense. It is a commercially available high-dose radiachromic dosimeter and would be suitable to monitor for passage of freshly irradiated fuel in a normally high-background location where other methods may saturate or be insensitive. As an example, the applicatior could be to monitor a small penetration where the dosimeter would be in close proximity to the diverted fuel and where the penetration is near the normal irradiated fuel transfer or storage area. Similarly, it could be used to verify declared irradiated fuel channels.

The basis of the commercial radiachromic dosimetry is the use of aminotriphenyl acetonitriles that are colorless precursors of a highly colored stable organic dye. Exposing a liquid or solid state solution of the compound to ionizing radiation can cause changes that result in reorganizing the molecule into the oye in an appropriate solvent activator. The integrated absoined dose is determined by measuring the optical transmission of the material at wavelengths where the dye absorbs strongly. The dosimeter absorption depends on the thickness of the absorber, and by making the dosimeters very thin, a very high dose range $\left(10^{4}\right.$ to $\left.10^{7} \mathrm{R}\right)$ can be covered. The threshold in a practical dosimeter yaries from $5 \times 10^{2} R$ in a $1-\mathrm{cm}$ path length solution to perhaps $5 \times 10^{4} \mathrm{R}$ in a 0.005-cm nylori or plastic host matrix for a solid state solution of the dye precursor. Typically the usable dose range of the dosimeter covers about three decades of dose above the threshold.

Radiachromic dosimeters are marketed by Far West Technology 10 ) in the form of impregnated papers and plastic or nylon sheets. Special fabrication is available for particular applications. Standard items include dosimeters at a price of about 0.20 US\$ per $1-\mathrm{cm}^{2}$ dosimeter, detector envelopes for light protection at about 0.04 US\$, and radiachromic readers at 415 US $\$$ each. Dosimeters are calibrated by batch, but the vendor recommends use of more than one to minimize variation. Calibration based on the expected exposure environment is recommended to determine the accuracy being achieved in routine use.

Drawbacks for radiachromic dosimeters are similar to other small dosimeters. Shielding is easy a. Id exposure to light or heat can destroy the latent information. Re-use is not possible.

\section{E. Superheated Drop Detectors}

A recently developed technique for radiation monitoring and dosimetry makes use of the bubble chamber principle wherein a superheated liquid is caused to nucleate gas bubbles by the presence of seed sites induced by radiation or particle interactions. The practical implementation of this principle is realized by forming small superheated drops dispersed in a gel-like host medium where they are held immobile. Each drop serves as a minjature bubble chamber and nucleation in one superheated drop consumes only that drop. The total amount of vapor released by radiation induced nucleation is a measure of the exposure and is easily determined if the host gel container is allowed to freely expand as gas bubbles are formed. Then the density of the dosimeter packet changes and this density change can be related to exposure through an appropriate calibration. The density measurement proposed uses a hydrometer-like arrangement in which a dosimeter packet with indicator stem is floated in a liquid. Other schemes for measuring the exposure include: electronically detecting the audible sound emitted during nucleation; collecting vapor into the top of a flexible disk-shaped container having ruled circles to measure the volume of released gas. 
At this time, the amount of work on superheated drop detectors has been sufficient only to support a patent application. Dosimeters are not available commercially. The principles have been demonstrated but many practical considerations are involved in application. The sensitivity of the dosimeter depends on the degree of superheat and therefore the temperature of the environment. A practical imit to the amount of superheat is the homogeneous nucleation limit, a temperature at which spontaneous nucleation takes place. Temperatures must remain below $3^{\circ} \mathrm{C}$ of the limit to have useable lifetimes. Six droplet compounds are mentioned in the patent and six examples are given for host materials and means of dispersing drops. Much work remains to be done to characterize them properly and determine the expected lifetime as a long-term monitor and to assess the effects of possible long-term composition changes.

The nature of the superheated droplet dosimeter makes it sensitive to fast neutrons ( $1-10 \mathrm{MeV}$ ) and gamma rays above about $6 \mathrm{MeV}$. As such, it would have high sensitivity to freshly irradiated fuel through detection of neutron emission. Thermal neutron sensitivity may come about by detection of energetic neutron capture gamma radiation. Proper attention to surrounding materials would be needed for most efficient use in a high neutron environment to minimize background.

The expected shortcomings for this dosimeter include its susceptiblity to other nucleation sources including heat, mechanical disturbance, and outgassing of the host medium. It has positive attributes including potentially low background, a high sensitivity to freshly irradiated fuel, no power requirement, it is easily read, and being a neutron detector, it is difficult to shield. It is not reusable but can be read at intervals during its lifetime.

\section{F. Electronic Pocket Dosimeters}

Pocket dosimeter and electronic film badge are terms used for small electronic instruments that consist of a radiation detector and circuitry to measure and announce the presence of a certain dose or dose rate of gamma radiation. In the past they have provided audible warning of the presence of dangerous radiation fields, but at present they are being used as personnel dosimeters in routine low-dose situations. Recent developments and future plans are such that it will be possible to sense and display both total dose and dose rate in one package, making pocket dosimeters of greater use than other types of personnel or environmental dosimeters.

The basic requirements for a pocket dosimeter include a radiation detector, electronic circuitry to detect and accumulate dose increments, a display mechanism, and a power source that is usually a small, sometimes rechargeable, battery. "Chirpers" are available that do not have memory and simply audibly announce the accumulation of a specified unit of dose, but the majority of units are integrating dosimeters that audibly announce and display discrete dose increments or can be read to display the accumulated dose.

Geiger-Mueller (GM) counters are used in most pocket dosimeters because they are small, simple, inexpensive, and have modest power requirements. The response of the GM counter to gamma radiation can be made to mimic tissue response by lightly shielding the GM counter with lead foil to reduce its somewhat higher response to low energy photons. The GM counter is thus well suited to dose measurement and the range of dose measured can be varied by choice of the physical size of the GM counter used and by the numerical size of the memory and display. A typical pocket personnel dosimeter using a GM counter, an internal LED display, and powered by a 9-V mercury transistor battery, has approximate 
front panel dimensions of $7.5 \mathrm{~cm} \times 3 \mathrm{~cm}$ and approximate length of $10.5 \mathrm{~cm}$. Its weight is typically 200 grams. The size and weight increase when rechargeable batteries or larger detectors are used.

Recently, the drawbacks of size and weight in GM counter personnel dosimeters have led to the use of cadmium telluride (CdTe) detectors in a chirper developed by Wolf, et al., (1979). Use of the CdTe room temperature semiconductor photon detector reduces the size of the dosimeter because CdTe, with a density around $6 \mathrm{~g} / \mathrm{cm}^{3}$, is a more efficient detector than a GM counter, and the needed operating potential is only a few volts compared to a few hundred volts for GM counters. Thia LASL-developed CdTe chirper mentioned has dimensions of $6.2 \mathrm{~cm}$ by $3.2 \mathrm{~cm}$ and $1.7 \mathrm{~cm}$ thickness and weighs only 50 grams. Commercial manufacturing and marketing of a CdTe chirper appears to be imminent and plans for developing a CdTe pocket dosimeter indicate that one may be available in about two years. The dose response of the CdTe detector used in the chirper is flat in the measured interval between $80 \mathrm{keV}$ and $1.3 \mathrm{MeV}$ making it a suitable substitute for the GM counter.

Precautions in use of electronic pocket dosimeters are fewer than for the nonpowered dosimeters. There are no adverse effects from humidity below $90 \%$, sunlight, heat below $55^{\circ} \mathrm{C}$, or prereading cleaning procedures. There is no inherent dose build-up or fading, and readout does not destroy the information. The electronic dosimeters are susceptible to being shielded, although in principle, shielding can be detected in a dose rate measuring instrument by simply monitoring for laroe dose rate decreases with additional circuitry. $R \cdot{ }^{\prime}$, and other soaking environments can cause failure of high voltage supply components ir. . sket dosimeters. A säit or corrosive chemical-laden atmosphere can ruin components or circuit boards, and mechanical shock can destroy circuit connections or the detector or introduce microphonic noise. The commonly encountered drawback to the electronic dosimeter is that all of the data can be lost if the battery fails. The problem is partially solved in units having a secondary power source used to maintain memory power after primary battery failure. In such units, replacing a dead battery returns the unit to its state at battery failure and the preserved accumulated dose can be read out or normal monitoring resumed.

The simplest electronic dose measuring device is the Eberline Personnel Radiation Monitor Model RT-1A, referred to as the RAD TAD. These have been marketed for many years and are familiar objects where $x$-radiography is carried out. The unit has the basic components of a GM counter, battery and high voltage power supply, integrator, and audible device driver for causing a chirp that starts at a dose rate of $0.1 \mathrm{mR} / \mathrm{h}$ and increases in frequency at higher dose rates. It is approximately cigarette-package size, weighs about 170 grams, and costs about 120 US\$. It does not meet the present requirements because it lacks memory and display, but Eberline does have plans for an improved version. The new device, as planned, will use a CdTe detector and will have integrated dose and dose-rate determination for alarm (chirp) and display purposes. The new device will use a microprocessor to minimize size and power needed for circuitry to monitor separate total dose and dose-rate alarm levels. To further reduce power, a liquid crystal display will be used for output dose or dose rate (switch selectable). The package is expected to be half again as long as the RAD TAD and will be approximately $6 \mathrm{~cm} \times 13 \mathrm{~cm}$ and $3.2 \mathrm{~cm}$ thick. When we first contacted Eberline in September 1979, the projected marketing date was Spring 1980. In March 1980, we learned that Eberline had been informed that the CMOS microprocessor selected for use would not be available in quantity for another year or more and further development had been postponed. We hope to follow the development in order to encourage inclusion of several other features we consider very desirable and which are described later. 
Another basic electronic integrating dosimeter, the digi/dose exposure dosimeter, is marketed by Reactor Experiments, Inc. 11) With slightly different names, other configurations to monitor different dose ranges are also offered. The price of the basic unit is 355 US $\$$ and the units are manufactured by XETEX,12) a manufacturer of digital radiation monitors, including some not marketed by Reactor Experiments. We have purchased the digi/microdose version because it covers the environmental range from 10 microR to 99 milliR and could be evaluated in our normal radiation environment. The digi/dose can be modified for use in a higher radiation region by changing the amount of prescaling used to increment the dose register and it can be further changed by increasing the size of the display register. The digi/microdose uses a $9-V$ transistor battery, preferably an alkaline type, for power. A high voltage supply produces regulated $500 \mathrm{Vdc}$ for a filtered GM counter. The counter pulses are prescaled in a pulse division circuit that produces one output pulse for each unit of dose accumulated. A driver circuit increments the display register, and the display and a buzzer are actuated for a short period of time at each output pulse. A remote signal output is also available for remote display or processing. A battery check circuit is used to indicate battery status. The battery lifetime is approximately 300 hours. We have found that lifetime is short for carbon/zinc batteries but extends beyond 300 hours with alkaline batteries. Display and other functions will operate for periods of several months, however, when the battery check no longer indicates a good battery, the detector voltage is reduced and efficiency decreases. The memory is preserved until the battery falls below $2.5 \mathrm{~V}$, and can be read out by placing a new battery in parallel with the old. Means to extend the battery lifetime are to delete the audible and visual display at each increment (this is done in a XETEX-marketed unit described later) or to use a larger battery, perhaps one with higher energy density such as a lithium cell. A larger battery could be used outside of the normal dosimete" package but inside of a tamper-indicating enclosure.

XETEX manufactures and markets a version of the pocket dosimeter, the Minigard Dosimeter Model 403B, that has no display and uses a separate reader to output results. The audible chirp is still present and is used to flag dose increments and a selectable total dose limit. Most features are similar to the digi/dose except that the dose increment to produce the chirp can be increased by switch selection to reduce power. A demand high voltage power supply is used to reduce power and with the added power saving through no LED display, a typical $9-\mathrm{V}$ transistor alkaline battery lifetime is six months. Another feature that distinguishes this dosimeter from the digi/dose is that turning off the power switch does not erase the memory. This feature is found in several other pocket electronic dosimeters. Preserving the record in memory can be done in two ways: 1) the main battery powers only the memory when the power switch is placed in the off position, and 2) a separate battery is used for memory power in any circumstance when main power is off, including main battery failure. XETEX uses the former approach and for some period of time after the battery voltage decays below $6 \mathrm{~V}$ (down to $2.5 \mathrm{~V}$ ), the memory is preserved even though the dosimeter no longer functions. The memory can be read out through the reader after adding a new battery in parallel. The size of the $403 \mathrm{~B}$ is slightly smaller than typical because it has no display; its price is only 160 US $\$$. The reader costs 290 US $\$$ and is a $115-\mathrm{V}, 60-\mathrm{Hz}$ unit, weighing $1.2 \mathrm{~kg}$ connected to the dosimeter by a cable for reading. The time required for reading is only two seconds after pushing the read button, allowing many dosimeter units to be read out in a short period of time. We ordered a standard 403B and reader from XETEX and one custom range dosimeter to evaluate the custom-design service. The modification we requested was an increased sensitivity with 1-microR dose increments suitable for rapid determination of environmental background levels. 
The modification requires a larger detector and larger package. The increase in prjce was modest, from 160 to 275 US $\$$ for a single unit order.

Victoreen markets the Primadose II Alarming Dosimeter, which is a displayless pocket dosimeter, and a reader much like the XETEX 403B. It is manufactured by Nuclear Associates, Inc., and the prices for the dosimeter and reader are 225 and 395 US\$, respectively. The Primadose is smaller than typical, $6 \mathrm{~cm}$ by $9 \mathrm{~cm}$ by $2-\mathrm{cm}$ thick, and weighs 120 grams. It uses a lightly shielded GM counter and has a flat dose response between $80 \mathrm{keV}$ and $1.2 \mathrm{MeV}$. The standard unit alarms at each increment of $1.5 \mathrm{mR}$ or each two detected pulses ty switch selection and at switch selectable integrated dose levels up to $0.8 \mathrm{R}$. The readout is three digits, $999 \mathrm{mR}$ maximum, in the standard reader. No tattery check is provided, but the reader does indicate battery condition as part of the read cycle and operation of the high voltage power supply causes a ticking sound that can be heard if the dosimeter is held against the ear. The battery lifetime for 40 hours per week operation of the Primadose is six months with the Mallory 1604 battery and one year with the Mallory MPl46X battery. The memory remains powered by the main battery when the power is switched off. Reading does not require that the dosimeter be turned on so data may be retrieved after the battery has decayed below normal operating voltage. Specific operating temperature limits of $0^{\circ} \mathrm{C}$ to $55^{\circ} \mathrm{C}$ and humidity limits of $0 \%$ to $90 \%$ relative humidity are given. We have purchased a Primadose II and reader and have found it to operate as advertised.

A pocket dosimeter, Model POR-1C, manufactured and marketed by Technical Associates 14 ) is a self-indicating dosimeter with a built-in display. It has switch-selectable alarm levels for total dose, a switch for battery test, and on/off and display/read controls. A separate bias cell is used tn maintain memory operation afte: main battery failure. Rechargeable batteriss are used and they have only 300 hours lifetime between charging. A polarity reversing characteristic of rechargeable batteries requires a protection circuit for the electronics that also facilitates switching on the bias cell. Other specifications are similar to the display dosimeters already discussed. Present cost is 280 US\$. We have obtained one PDR-IC to test in a mode where host power is available for trickle charging.

The last digital pocket dosimeter considerad, the DOS-I manufactured by $K$ immel, 15) has many of the features discussed earlier: rechargeable batteries, audible and visjble output, typical detector and energy response, and typical electronics. The DOS- 1 also has some unique features. A liquid crystal display is used and because of its low power consumption can be on constantly. The total dose alarm level can be set in unit iricrements and a dose-rate alarm is included at a fixed threshold. Finally, the cosimeter can be read in an electronic reader compatible with computer processing and a self-test function is included to exercise both audible and visible displays when the dosimeter is operating normally and the battery is charged. Price for the DOS-1 is 395 US $\$$ and it is expected to be available in the United States in October 1980.

The CdTe chirper developed at LASL by Wolf, et al., is being prepared for marketing in Summer 1980 at RMD, Inc. 16) Advertising shows a package used for the LASL prototype. A lithium battery is planned with a six-month lifetime projected, and a 300 US $\$$ price is anticipated. If other possibilities for a small-volume, low-power monitor are unsuccessful, RMD probably has the means to develop the required extensions of the basic chirper provided development funds can be supplied.

In surrimary, the electronic dosimeters have the desirable attribute of being unaffected by most environmental hazards, relatively inexpensive, quickly and easily read (readings may be obtained at any time and may be followed by resetting or not), designed 
with memory survival on battery failure, and can, in principle, be made to detect the emplacement of shielding material. The most desirable features of electronic dosimeters for YES/NO monitor application are low-power CMOS electronics, memory preservation in the event of power loss, low-power detector voltage supply, and low-power liquid crystal display or separate reader to further reduce power. The choice of detector can be made to meet spact and power requirements; the inherent radiation detection properties can be made similar for CdTe and GM counters. The battery lifetime requirements for use of electronic dosimeters with yearly interrogation can be met using lithium batteries. Table I shows properties of common battery types. The claimed six-month lifetime for the XETEX dosimeter is based on using a $9-V$ alkaline transistor battery of $16 \mathrm{~cm}^{3}$ volume. Using a lithium battery of the same volume provides more than double the energy content and should extend operation to one year. Using lithium batteries, perhaps three AA size cells, should give the required lifetime, and to protect the memory, a separate smaller lithium cell can be used ( $2.5 \mathrm{~V}$ is all that is needed). The separate cell is needed because the flat discharge curve of lithium cells causes failure to occur abruptly. The sloping discharge curve for alkaline cells allows failing batteries to preserve the memory for a longer period of time.

Rechargeable batteries are another possibility. The cells are sized to maintain operation during line power failure and are continuously trickle chargod. The battery charger and battery failure detector require additional circuitry.

TABLE I

CHARACTERISTICS OF COMMON BATTERIES

\begin{tabular}{|c|c|c|c|c|c|}
\hline Name & Zinc Carbon & Alkaline & Mercury & Lithium & Nickel Cadmium \\
\hline $\begin{array}{l}\text { Basic cell } \\
\text { open circuit } \\
\text { voltage }\end{array}$ & $1.5 \mathrm{~V}$ & $1.5 \mathrm{~V}$ & $1.35 \mathrm{~V}$ & $2.95 \mathrm{~V}$ & $1.2 \mathrm{~V}$ \\
\hline$w \cdot h / 16 \mathrm{~cm}^{3}$ & 2 & 3 & 6 & $8-13$ & 1.7 \\
\hline $\begin{array}{l}\text { Storage Life } \\
\left(20^{\circ} \mathrm{C}\right)\end{array}$ & $1-2$ yrs & $2-3$ yrs & $3-4$ yrs & 10 yrs + & 1 month \\
\hline $\begin{array}{l}\text { Low temperature } \\
\text { performance }\end{array}$ & poor & good & poor & excellent & $\begin{array}{l}\text { good } \\
\text { (poor at high } \\
\text { temperature) }\end{array}$ \\
\hline $\begin{array}{l}\text { Shape of } \\
\text { discharge curve }\end{array}$ & sloping & sloping & flat & flat & flat \\
\hline
\end{tabular}


A large number of radiation monitors are available to carry out tasks similar to those performed by the dosimeters already discussed, but they differ in having greater bulk, weight, and cost. They also have the possibility of greater sensitivity, precision, and information capacity. One instrument already being evaluated by the IAEA is a Reactor Power Monitor developed under ISPO Task E.24 by Dowdy, et al. (1979). The basic requirements for tamper-indicating enclosure, power continuity, and data recording are present in that unit. Its detector may not be optimum, but the changes required to use a $\mathrm{NaI}$ or Bismuth Germanate ( $\mathrm{Bi}_{4} \mathrm{Ge}_{3} \mathrm{O}_{12}$ or $\mathrm{BGO}$ ) detector are relatively small modifications and these gamma-ray detectors are applicable to a large number of monitoring situations. In addition to recording the averages as is presently done, more extensive modifications, including reprogramming, could provide recording of events that cause major increases or decreases of dose rate. The record produced from stored information in this more elaborate monitor contains a time record of radiaticn levels and thus gives dose rate information. In principle, the record could indicate reductions in background caused by shielding of the monitor. Increases in dose rate caused by irradiated fuel passage can be compared to recent background levels rather than a yearly sum of background, thereby increasing the sensitivity obtained.

\section{H. Other Radiation Detectors}

An ISPO task carried out at Sandia Laboratory, Albuquerque (W. K. Ream, et al., 1979), surveyed nonoptical techniques for surveillance in IAEA safeguards application. On: type of detector considered in that study detects infrared (IR) rafiation and is possibly applicable to YES/NO monitor application. The task report describes the use of IR detectors for SNM vault inventory use, but the task in our study is simply the inverse problem, verification of absence of SNM, and the thermal radiation detectors should be applicable. Detecting the transient presence of warm safeguarded materials seems possible using the IR technique, and detection of shielding also seems possible. We have found one detector package that is small, simple, inexpensive, and applicable to YES/NO situations.

Dexter Research Center, Inc. 17) markets an IR control, the Thermacon, that is $11-\mathrm{cm}$ square by $5.4-\mathrm{cm}$ thick, weighs $140 \mathrm{~g}$ and can be battery powered with a 9-V battery. Battery lifetime is shorter than in typical dosimeters, but could be extended by using lower power integrated circuits. The package uses a thermopile IR detector and logic circuitry to detect temperature changes in its field-of-view and the unit is sensitive to IR. radiation from objects in the room temperature range. Collimators are used to define the field-of-view and the T80 Model has logic circuits to detect increases or decreases in the mean temperature of the field-of-view. Thus, it can detect a human body entering the field or a piece of paper or shield obscuring the field-of-view. The unit as now sold would need additional circuitry, similar to dosimeter circuitry, for accumulation and display of alarm conditions. Cost of the basic control is 80 US\$.

I. Summary of Dosimeter Characteristics

Figure 1 shows the RPL rod dosimeter used by the Agency along with relative sizes of other dosimeters considered in this report.

The characteristics of the dosimeters that have been discussed are briefly summarized in Table II. 


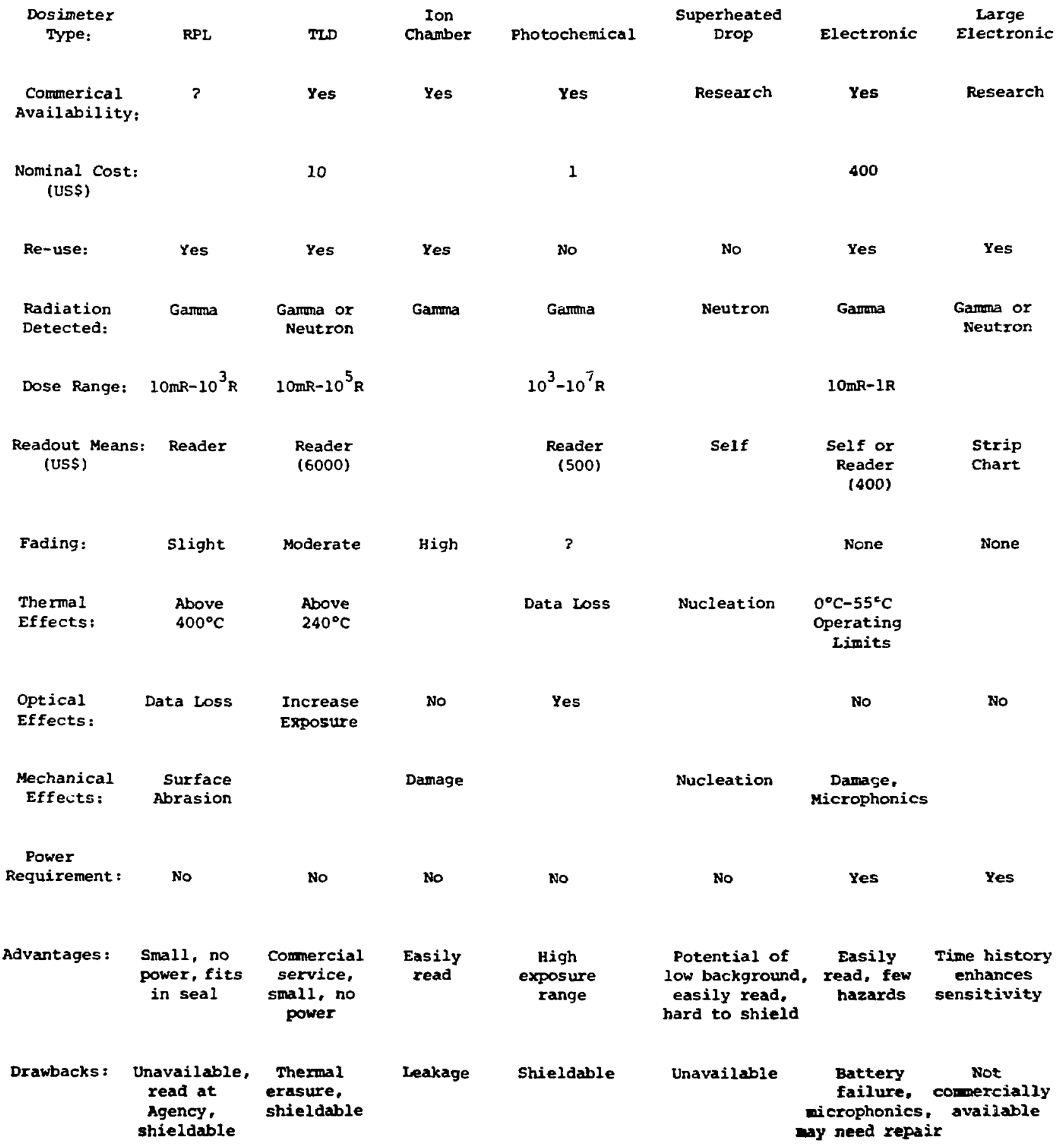




\section{TARGET CHARACTERISTICS}

The goal of IAEA safeguards is to prevent the diversion of weapon grade nuclear material from nonweapon applications to weapon production. The materials to be safeguarded include plutonium and enriched uranium. The most sensitive application of surveillance monitors is the safeguarding of plutonium because plutonium produces the greater amount of penetrating gamma radiation. Plutonium in fabricated items not for weapon use is found both in the form of reactor fuel--for instance fast critical assembly fuel, and as plutonium formed during reactor exposure of uranium or mixed oxide reactor fuel. Past Agency usage of YES/NO monitors has been in safeguarding plutonium present in spent reactor fuel at one reactor, and has been described by Schaer (1977). He estimates that the YES/NO monitor must be capable of measuring a dose during passage of irradiated fuel between $500 R$ and $10,000 R$, while also being capable of recording backgrounds between $1 R$ and $100 R$ on a year-long interval should no irradiated fuel pass. That study, using RPL dosimeters, found that integrated background levels at selected nonrout ine fuel transfer points were about $10 \mathrm{R}$ or less during a two-month exposure. The net dose at a routine discharge port was $290 \mathrm{R}$ from the passage of one fuel assembly having an exposure of about 3800 megawatt days per metric ton uranium (MWD/MTU). The measured dose accumulated during passage of the irradiated fuel depends on the distance between fuel and dosimeter as well as the rate of passage and fuel shielfing. While details are not given by Schaer, Sanatani (1979) indicates that $20-$ to $30-\mathrm{cm}$ spacing between fuel and dosimeter is typical and passage speed is usually no greater than $10 \mathrm{~cm} / \mathrm{s}$. Further variables affecting the measured dose are the fuel exposure, operating power history, and the cooling time of the fuel.

The ability to detect diversion depends on differentiating between normal background levels and the abnormal levels produced by irradiated fuel passage. In commonly used detection schemes, the background is well established and oiversion can be detected when it produces a signal larger than some multiple of the standard deviation of the background. As a result, when the background does not vary, a monitor can detect signals that are a small fraction of the background. In the case of YES/NO monitors, the situation differs because the background and its variation during the course of a year are not well established. It simply is not feasible to determine a precise background in the best manner of measuring for 10 to 20 times the signal interval because that would take 10 to 20 years. So, backgrounds levels will be established either through short-term measurements or by comparison of results among all monitors used in locations expected to have similar backgrounds. As a result, the criterion used for detection would need to be a signal that exceeds the background by some multiple of the background itself and the exact criterion used will have to be established after observations have been made to determine the variability of background. In Schaer's discussion, he uses a factor of five between the maximum background estimates and the minimum irradiated fuel signal and in his example, the $290-R$ net signal is clearly differentiated from the expected background for one-year exposure of about $60 \mathrm{R}$ and is about at the detection level if the factor of five is used.

In order to compare the example given by Schaer to other circumstances, we can look at how the detected signal would vary with changes in irradiation time, cooling time, and the manner of passage. We can use the decay power function (power is derived from gamma-ray and particle decay but the time dependence is the same) given by Glasstone and Sesonke (1967)

$$
P / P_{0}=6.1 \times 10^{-3}\left[\left(T-T_{0}\right)^{-0.2}-T^{-0.2}\right]
$$

where the reactor power level is assumed constant, $T_{D}$ is the irradiation time and $T$ is 
the irradiation plus cooling time. Assuming a nominal power level in each bundle is $830 \mathrm{~kW}$ and each bundle contains $18.5 \mathrm{~kg}$ of uranium, an approximate irradiation time of 85 days for Schaer's example is obtained. The relative power output and gamma radiation intensities calculated for different fuel irradiations based on these assumptions is given in Table III for 1-hour and 30-day cooling times.

Keep in mind that the gamma-ray intensities in Table III are normalized to the 3800 MWD/MTU irradiation in each separate case. Table IV can be used to compare the intensities for each irradiation and at the cooling times used in Table III.

TABLE III

RELATIVE GAMMA-RAY INTENSITY VERSUS BURNUP AT FIXED OPERATING POWER

\begin{tabular}{ccr}
$\begin{array}{c}\text { Burnup } \\
\text { (MWD/MTU) }\end{array}$ & $\begin{array}{c}\text { Relative Gamma-Ray } \\
\text { Intensity at One Hour }\end{array}$ & $\begin{array}{r}\text { Relative Gamm } \\
\text { Intensity at }\end{array}$ \\
\cline { 2 - 3 } 500 & 0.85 & 0.29 \\
1000 & 0.91 & 0.49 \\
2000 & 0.95 & 0.79 \\
3800 & 1.00 & 1.00 \\
7600 & 1.04 & 1.52
\end{tabular}

TABLE IV

RELATIVE GAMMA-RAY INTENSITY VERSUS IRRADIATION

Burnup (MWD/MTU)

500

1000

2000

3800

7600
Intensity at 30 days/Intensity at One Hour

0.022

0.035

0.055

0.067

0.105

The effects of fuel history can be summed up for this example by noting in Table III that the fuel burnup has minor influence early on but with increased cooling time becomes more noticeable. The overpowering decrease in signal strength is simply from decay with time as shown in Table IV. In fact, after only about 10 days the monitor dose accumulated during fuel passage would equal the background in Schaer's example. It should be remembered that specific assumptions were made in these calculations in order to estimate which parameters are most important. Specific cases can always be calculated given the complete specifications.

The variation in detected signal caused by the manner of passage depends on the passage speed, the passage distance, and shielding materials. The detected signal is 
expected to vary inversely with the first power of the speed of passage. The detected signal has dependence on distance between (distance)-2 and (distance)-1, and in this instance, the fuel would be near the detector and appears as a line source so that the variation is most likely proportional to the inverse distance. Just as important as distance is build-up of signal caused by secondary gamma-ray flux from scattered radiation, fluorescence radiation, neutron capture gamma radiation, and Bremsstrahlung from the interactions of the primary radiation with structural materials near the dosimeter. In practice, it will be most expedient to carry out measurements in typical surroundings to determine typical signals. Shielding of diverted fuel can be done with an appropriately designed shield capable of dissipating the heat load. The dimensions given by Sanatani allow thick shields, but only a few centimeters of lead is needed to reduce the detected signal below background. The qualitative form can be used for the transmitted gamma-ray flux $e^{-\mu \chi} \chi^{k}$ given by Blizard and Abbott, where $\mu$ and $\chi$ are the usual linear absorption coefficient and thickness of the shield and $\chi^{k^{\prime}}$ ( $k$ is a material and gamma-ray energy dependent constant) is a term representing the gamma-ray build-up in the shield. With a 3-cm thickness and using $1 \mathrm{MeV}$ as a representative gamma-ray energy, the transmission is just $15 \%$.

In contrast to irradiated fuel that has high radiation levels of approximately $10^{5}$ $\mathrm{R} / \mathrm{h}$ at $25 \mathrm{~cm}$ for fresh high-exposure fuel, the plutonium fuel for fast critical assemblies has for the most part only the intrinsic radiation from the isotopes $239_{\mathrm{Pu}}$ and $241_{\mathrm{Am}}$ contained. Dose rates at $25 \mathrm{~cm}$ measured in our laboratory are about $2 \mathrm{milliR} / \mathrm{h}$ from $239 \mathrm{Pu}$ and about $28 \mathrm{milliR} / \mathrm{h}$ from $241 \mathrm{Am}$ in one manufacturer's fuel plate--a 2.54-cm plate containing $25 \mathrm{~g}$ of plutonium with an $11.6 \% 240 \mathrm{Pu}$ content P-U-Mo alloy. Dose rates from larger plates scale with length and other fuel types emit from 0.67 to 1.26 times as mich $239 \mathrm{Pu}$ radiation and 0.4 to 4.5 times as much $241 \mathrm{Am}$ radiation based on measurements by Caldwell (1978). The larger variation for $241 \mathrm{Am}$ is caused by a large variation of the $24 \mathrm{l} \mathrm{Pu}$ content, the precursor of the $241 \mathrm{Am}$ contained in the fuel. For some dosimeters the $241 \mathrm{Am}$ variation doesn't matter because the predominant $60-\mathrm{keV}$ radiation is too soft to detect; this is the case for filtered dosimeters that have little efficiency below $80 \mathrm{keV}$. Similarly, only light shielding is required to eliminate the $60-\mathrm{keV}$ radiation entirely from detection by any dosimeter.

In comparison to the larger signal from passage of an irradiated fuel bundle containing approximately $60 \mathrm{~g}$ of built-up plutonium at most, a 60-g mass of plutonium in fuel plates produces a signal smaller by a factor of approximately $4 \times 10^{-8}$. As a result, fresh plutonium fuel monitoring on a yearly basis cannot achieve useful sensitivity even in a low background environment that would decrease the needed signal disparity to perhaps a factor of $10^{-4}$. Even an hourly monitoring period would succeed only for intimate source-to-detector distances. Fresh fuel monitoring requires more sophisticated monitors such as those now used for portals, packages, and vehicles where timely background measurements allow good sensitivity for low-source strength detection.

\section{TAMPER-PROOFING}

Tamper-proofing a YES/NO monitor is really the means to assure at retrieval time that nothing has occurred that could alter the performance of the monitor and that stored information has not been altered. The first step is to deny contact with the dosimetric material or apparatus by enclosing the dosimeter in a tamper-indicating container. The Agency practice with RPL dosimeters has been to enclose the dosimeter in a general purpose seal. The seal is retrieved, returned to the Agency and then markings inside of the seal are used to verify sameness and the dosimeter is read out. A similar approach is used by Dowdy, et al. (1979), where a reactor power monitor case is used as a 
tamper-indicating enclosure and seals are used to verify integrity of an attachment lug and security seal tangs are provided to verify that the case halves have not been separated. Enhancement of the flaw-indicating capability is described by Mangan (1979) in the use of anodized aluminum. Smathers (1979) described using colored anodized aluminum and stressed glass for an equipment enclosure that is secured by an optical fiber seal passing through holes in attachment bolts. In practice, all of the dosimeters described can be enclosed in an aluminum container without altering performance of the dosimeter. The IR sensor cannot be totally enclosed because a viewing opening is required. The T80 sensor unit is self-protecting even with an opening because it alarms on increase or decrease of ambient levels. The aluminum containers can be secured in place by a seal and tang as is now done with RPL dosimeters or by using a grouted stud as is done for the reactor power monitor.

The integrity of the container itself can be verified by using a marking scheme used in general purpose seals or with the unique pattern of fiber optic seals.

In order to protect against the adverse effects of humidity on some dosimeters, the container can be hermetically sealed with elastomer gaskets. An indicating-desiccant material can be used to verify the integrity of that seal. The hermetically sealed aluminum case should provide adequate protection against corrosive chemicals and uv light. Temperatures above $40^{\circ} \mathrm{C}$ in discrete steps can be recorded by using temperature-indicating devices based on fusible materials or irreversible color changes, and erasure of heat sensitive data can be 'etected by use of an appropriately calibrated device. Such indicators are widely available and inexpensive.

Mechanical isolatior of an electronic dosimeter to prevent harm or to eliminate microphonics can be accomplished using resilient foam or fiber insulation between dosimeter and case.

The costs involved in the tamper-proofing can be made small. Formed cases are readily available (Zero Cases) and are inexpensive and a sealed, bolt-attached lid would not add much expense. Once designed, gasketing, desiccant, and temperature indicators will add only a few dollars. The complete container should be at most a few hundred dollar (US) item even if colored anodizing is used.

\section{OPTIMAL MONITOR APPLIĊATIONS}

The measure of the effectiveness of a monitoring system in which there is relative : notion between radiation source and monitor is often done with estimation of detector range, which is represented by the near-miss distance, for the monitor-source combination. In the case of complex monitors where backgrounds have statistical variation as the primary variant, a detection range can be calculated by determining the background count and the signal count accumulated during the passage time interval and equating them through the relationship used as a detection criterion. When this is done for a gamma-ray detector and gamma-ray source having a falloff of intensity with the inverse square of the distance and using as a detection criterion the requirement that the signal counts exceed some multiple of the standard deviation of the background (represented by the square root of the background count), the result is that the detection range is proportional to the factor

$$
\left(\frac{N S_{0}}{v B}\right)^{1 / 3}
$$


This result shows that detection is enhanced by increasing the number of detectors, $N$, or by decreasing the relative velocity $v$. Also, any means of enhancing detector efficiency even though it may increase both the background, $B$, and the net signal, $S_{0}$, will better the detection range. Thus, in this case, increasing the detector geometrical or intrinsic efficiency serves to enhance the detection range.

For YES/NO monitors, the detection criterion is different and is likely to use a comparison between a measured result and a level derived from previous or similar measurement when background conditions prevailed. The trigger level so derived is likely to be related to the actual background by some multiple, $M$. Then the detection criterion can be expressed as

$$
\frac{\pi N S_{0}}{r_{0}}+N B \geq M N B
$$

where $r_{0}$ is the near miss distance and the two B's represent a previously measured background used to derive the threshold value on one hand and the background during monitoring on the other. The same symbol is used in both cases because the constant $M$ must be large enough to insure that any variability in background does not cause a false alarm, so for this comparison the B's can be considered the same. Then the detection range is proportional to the factor

$$
\frac{\mathrm{S}_{\mathrm{o}}}{\mathrm{vB}}
$$

In this case, optimization of detection comes about when relative velocities are minimized, but notice that detector changes that affect signal and background in the same proportion do not better the monitor performance. Better sensitivity comes about only through changes that increase the signal without increasing background to the same degree and useful considerations for this include minimizing source-monitor distance, using a gamma-ray spectral window that includes a greater relative proportion of signal than background, minimizing the amount of shielding between source and monitor, and decreasing the monitoring time period so that the background is reduced relative to the fixed signal. The most useful conclusion from this analysis is that using multiple detectors or increasing the size of a detector is unlikely to improve sensitivity. Because personnel dosimeters are much alike in their spectral response, spectral response cannot be used as a selection criterion. Differences in intrinsic efficiency alone do not improve performance. This conclusion is reached independent of the value of $M$.

A discussion on whether to use simple gamma-ray detectors or neutron-specific detectors should be included. The analysis for neutron detection ranges is more difficult because scattering by surrounding structure can influence greatly the neutron spectrum and intensity. The result is similar to that for gamma rays, especially for fast neutron detection at short distances, and ultimately, comparative measurements are needed to make a complete analysis. The neutron source strength is numerically much smaller than the gamma-ray source strength, particularly early in the cooling period when photoneutrons may be the largest single neutron component. In a well-defined background situation, greater intensity makes the gamma-ray approach best. For surveillance monitors, knowledge of background is essential to make a complete comparison and a background survey of gamma rays and neutrons at typical monitor locations is required.

Now that the type of monitor detector has been shown to be of secondary consideration, specific applications can be discussed. What is needed to determine 
applicability is primarily knowledge of background levels at the monitor location and knowledge of the dose accumulated by a dosimeter at a similar location durirg a typical passage of a typical source according to the anticipated diversion scenario. For applications that involve nonitoring plumbing or duct systems, the major difference from open air monitoring is the attenuation of radiation in the intervening materials.

Secondary considerations that need to be addressed include complexity, maintenance, expense, etc. The RPL system now in use is very simple and the dosimeters are small, requiring little in the way of installation, maintenance, and transport; however, disadvantages of the system are limited availability and the need to return the dosimeters to the Agency for reading. These disadvantages are not encountered with the use of electronic dosimeters but the dosimeter cost increases, the tamper-proofing requirements are more costly, there is a need to replace batteries at a cost of approximately 20 US\$ per battery, and other maintenance may be required. The one advantage to the electronic dosimeter is immediate readout, although the tamper seals still must be returned to the Agency for verification of integrity.

It is apparent that routine monitoring can be carried out effectively as is now being done. If new RPL dosimeters are not available commercially, the most effective remedy may be to find stores of unused dosimeters and acquire them, or to investigate the possibility of obtaining new equipment through a cooperative effort with one of the large scale programs purchasing systems in quantity as mentioned in Section II.A. Switching to TLD dosimeters could solve the availability problem and use of a TLD service could relieve the Agency of the reading task. However, a larger tamper-proof container is needed and a temperature monitor must be included.

\section{SUMMARY AND RECOMMENDATIONS}

A variety of personnel dosimeters have been examined to determine their operating characteristics and advantages and shortcomings for application as surveillance monitors. An analysis of the recessary detection criterion resulted in the conclusion that in this application, detectors used in personnel dosimetry are equivalent in performance and that higher intrinsic efficiency brings no definite advantage. The conclusion was made that considerations of simplicity and convenience, although secondary, are the most important considerations. Further analysis of the application of surveillance monitors depends heavily on the availability of data representative of the background levels expected and also of the signals to be monitored. The recommendation was made to continue present practice, if possible, using RPL dosimeter's because it seemed to be as effective as any other approach and is very simple and easily tamper-proofed.

A further recommendation is the: the Agency accumulate the reference exposure data needed to further analyze the application of YES/NO monitors. In order to carry out such data accumulation, the electronic dosimeters would be of highest utility for gamma-ray data because they are so easily read out. LiF dosimeters are perhaps the easiest for acquiring neutron data. The needed background data can be acquired in two stages: one being a quick survey of levels at many locations using electronic dosimeters now commercially available; the second, to acquire at some selected locations, measurements over long periods of time with, if possible, readings at several time intervals. This second step will require some amount of tamper-proofing. Source data also can be obtained conveniently with the electronic dosimeter. 
The one problem mentioned that can defeat surveillance monitors is covert shielding of the monitor during diversion. The one means of detecting shielding is by using an electronic monitor having a dose-rate detection capability that will detect increases or decreases in sensed dose rate. Such an instrument does not exist in a convenient small unit now and perhaps it would benefit the Agency to sponsor the development of a prototype small instrument and use it to determine operational levels of dose-rate clnange. What is required is not only to detect dose rate but also to record it. It would be most useful to have a time record although monitoring could be done with a single event register. Information on dose-rate changes will enable estimation of the usefulness of that added feature in a surveillance monitor.

Another technique to detect shielding and a possible YES/NO monitor by itself is the IR monitor in Section II.H. This is a new commercial item and information about its sensitivity and possible drawbacks are not now available. It would be beneficial to investigate the performance of the Dexter Research Thermacon for possible application as a surveillance monitor in areas that have no motion taking place in the monitor's field-of-view--monitoring ducts or pipes, as for instance, where a rise in the surface temperature could flag irradiated fuel passage. Similarly, the Thermacon could be used to view a stationary external point from within a tamper-proof enclosure and used to detect shielding being placed around a dosimeter monitor.

A summary of possible applications of the jiscussed dosimeters is given in Table $V$.

\section{TABLE $V$}

SOME SPECIFIC APPLICATION POSSIBILITIES

Application

Routine

YES/NO Monitor
Device

RPL dosimeter

TLD dosimeter packaged with thermal indicator

Electronic dosimeter

Data Base Acquisition
TLD dosimeter (gamma and neutron)

Electronic dosimeter
Source

$?$

Commerical vendor plus packaging developed under ISPO task

ISPO task to develop one having increase/ decrease detection of dose rate

Commerical vendor

Commercial vendor 
1) Prof. Y. Nishiwaki

Toshiba Glass Company, Ltd.

Mori Bldg., Shinbashi Annex 2F

35-10, Shinbashi 5-Chome, Minato-Ku

Tokyo, 105, Japan

Address for 1980: Prof. Y. Nishiwaki Jagdschlossgasse 91

A-1130 Vienna, Austria

2) Mr. T. Ohmori

Toshiba Glass Company, Ltd.

Mori Bldg., Shinbashi Annex $2 F$

35-10, Shinbashi 5-Chome, Minato-Ku

Tokyo, 105, Japan

3) Mr. T. Aoki

Toshiba international Corporation

New York, NY

Telephone: 212/682-8416

4) SEI, Ltd., Manchester, UK

c/o Mr. Thomas Parkinson

F isher Controls, Ltd.

Century Works

Lewisham, London, SE 137 LM

5) Frieseke and Hoepfner, Gmbh

Erlanger-Bruck, Germany

6) R. A. Stephen and Company, Ltd.

Miles Road, Mitcham, Surrey CR4 34P

England

7) Eberline Instrument Corporation

P. O. Box 2108

Santa Fe, NM 87501

8) Victoreen, Inc.

10101 Woodland Avenue

Cleveland, $\mathrm{OH} 44104$
9) Harshaw Chernical Co. 6801 Cochran Road Solon, $\mathrm{OH} 44139$

10) Far West Technology 3300 South Kellogg Goleta, CA 93017

11) Reactor Experiments, Inc. 963 Terminal Way San Carlos, CA 90470

12) XETEX, Inc. 650 National Avenue Mountain View, CA 94043

i3) Nuclear Associated, Inc. 100 Voice Road Carle Place, NY 11514

14) Technical Associates 7051 Eton Avenue Canoga Park, CA 91 303

15) Kimmel, Inc.

118 Ridgeway Center Oak Ridge, TN 37830

16) RMD, Inc. 44 Hunt Street Watertown, MA 02172

17) Dexter Research Ctr, Inc. 7300 Huron River Drive Dexter, MI 48130 


\section{BIBLIOGRAPHY}

\section{RPL Glass}

H. Francois, et al., "Personnel Dosimetry Systems for External Radiation Exposures," Technical Report Series 109, IAEA, Vienna, Austria, 1970.

Klaus Becker, Solid State Dosimetry, CRC Press, Cleveland, Ohio, 1973.

G. A. Dorofeev and S. Somasundaram, IAEA International Glass Dosimetry Intercomparison, 1970, in Advances in Physical and Biological Radiation Detectn:s, IAEA, Vienna, Austria, 1971.

Manufacturer's Literature:

Toshiba Glass Company, Ltd., "Fluoro-Glass Dosimeter and Glass for Fluoro-Glass Dosimeter."

Robert Schaer, "Health Dosimeter Plays an Unusual Role as a Safeguards Device," IAEA Bulletin, Vol. 19, No. 2.

Thermoluminescent Dosimeters

Klaus Becker, Solid State Dosimetry, CRC Press, Cleveland, Ohio, 1973.

Glenn F. Knoll, Radiation Detection and Measurement, John Wiley and Sons, New York, New York, 1979.

H. Francois, et al., "Personnel Dosimetry Systems for External P.adiation Exposures," Technical Report Series 109, IAEA, Vienna, Ausìria, 1970.

Per Spanne, "Theroluminescence Dosimetery in Ln: MicroGy Range," Acta Radiologica Supplementum 360, 1979.

Manufacturer's Literature:

Eberline, "Radiation Dosimetry TLD Service for Personnel and Environmental Monitoring."

Victoreen, R. P. Ulman, "Victoreen Thermoluminescent Dosimetry."

Harshaw, Donald E. Lancaster, "Thermoluminescence: Theory and Applications;" F. Morgan Cox, "New Solid Lithium Fluoride Thermoluminscent Dosimeters."

W. B. White, et al., "Use of Harshaw Model 2000 for Thermoluminscent Analysis of Environmental Background Leve: Dose Measurements."

Film and lon Chambers

National Council on Radiation Protection and Measurements, "Instrumentation and Monitoring Methods for Radiation Protection," NCRP Report No. 57. 
H. Francois, et al., "Personnel Dosimeters, etc.," as quoted under RPL glass. Manufacturer's Literature:

R. A. Stephen and Co., Ltd., R. W. Hawley, "Quartz Fibre and Phosphate Glass Dosimeters," 1964.

\section{Radiachromic}

K. C. Humphreys and A. D. Kantz, "Dosimetry and Quality Controi in Electron Beam Processing," IEEE Transactions in Nuclear Science, Vol. NS-126, No. 1, 1979.

Manufacturer's Literature:

Far West Technology, Inc., "Radiachromic Dosimetry Materials," Radiachromic Note 4.

\section{Superheated Drop}

Robert E. Apfel, "The Superheated Drop Detector," Nuclear Instruments and Methods 162, 603, 79; United States Patent 4143 274, March 6, 1979.

\section{Electronic Pocket Dosimeters}

M. A. Wulf, C. J. Umbarger, and G. Entine, "Use of a Cadmium Telluride Detector in a New Tiny Personal Radiation Chirper," IEEE Trans. Nuc. Sci. NS-26, 1, 1979.

O. R. Mulhern, W. T. Barlett, and C. D. Hooker, "Pocket-sized Electronic Dosimeter Testing," Battelle Pacific Nor thwest Laboratory report, PNL-2548, 1979.

U. S. Nuclear Regulatory Commission Office of Standards Developments, Draft Regulatory Guide, "Audible-Alarm Dosimeters," August 1979.

R. W. Graham, "Primary Batteries," Moyes Data Corporation, Park Ridge, NJ, 1978.

M. Grossman, "Focus on Batteries," Electronic Design 12, 88, 1978.

J. Lyman, "Battery Technology," Electronics, April 3, 1975, p. 75.

Manufacturer's Literature:

Reactor Experiments, Radiation Monitoring Instruments and Instruction Manual, Digi/microdose Model $811 \mathrm{~B}$.

XETEX, Mini-gard System.

Victoreen, Operat.ing Manual, Primadose II.

Technical Associates, Catalog.

Kimmel, Product Catalog. 
Dosimeter Corporation of America, Catalog 791.

Union Carbide Corporation, "Eveready Battery Applications and Engineering Data," 1971.

Mallory Battery Company, Catalog, 1979.

Gould, Inc., Portable Battery Division, Catalog, 1979.

Electrochem Industries, Inc., Catalog, 1979.

\section{Large Electronic Monitors}

E. J. Dowdy, A. A. Robba, R. D. Hastings, and S. W. France, "A New Instrument for Confirmation of Declared Power Histories of Central Station Power Plants," Nuclear Materials Management VIII, Proceedings Issue, p. 689, 1979.

\section{Other Radiation Detectors}

W. K. Ream, W. D. Arlowe, D. S. Miyoshi, and A. E. Birden, "ISPO Task E.20, Status Monitoring Alternate to Optical Surveillance," Sandia Laboratories report, SAND 79-15873, 1979.

Manufacturers Literature:

Dexter Research Center, Thermacon data sheet.

\section{Target Characteristics}

Robert Schaer, "Health Dosimeter Plays an Unusual Role as a Safeguards Device," IAEA Bulletin 19, No. 2, 31, 1977.

S. Sanatani, private communication, 1979.

Samuel Glasstone and Alexander Sesonske, Nuclear Reactor Engineering, Van Nostrand Reinhold Company, New York, p. 100, 1967.

E. P. Blizard and L. S. Abbot, Reactor Handbook, Volume III, Part B, Shielding, Interscience Publishers, New York, p. $111,1962$.

J. T. Caldwell, unpublished data, 1978.

Dilworth, Secord, Meagher and Associates Ltd., "Diversion Path Analysis of Gentilly-2 Generating Station," Report No. 765/930, 1977.

A. B. Johnson, Jr., "Behavior of Spent Nuclear Fuel in Water Pool Storage," Battelle Pacific Northwest Laboratories report, BNWL-2256, 1977.

V. H. Allen and A. J. Sterling, "Performance of a Prototype Spent Fuel Bundle Counter for 600 MW CANDU Reactors," Nuclear Materials Management, Proceeding Issue, p. 733, 1979. 
Nuclear Engineering International, "Survey of Canada," Nuclear Engineering International, June 1974, p. 475-514.

\section{Tamper-Proofing}

E. J. Dowdy, A. A. Robba, R. D. Hastings, and S. W. France, "A New Instrument for Confirmation of Declared Power Histories of Central Station Power Plants," Nuclear Materials Management VIII, Proceedings Issue, p. 689, 1979.

Dennis L. Mangan, "A Personnel Portal for International Research Facilities Safeguards," Nuclear Materials Management, Proceedings Issue, p. 675, 1979.

Douglas C. Smathers, "A Tamper Recorder for Unattended Safeguards Instruments," Transactions of the American Nuclear Society, TANSAO 33 (Suppl. 1), 23, 1979.

Manufacturer's Literature:

Markson Science, Inc., 1980 Markson Catalog, Temp Plate and Temprobe Temperature Recorders, p. 170.

\section{Optimal Monitor Applications}

D. G. Boase and J. D. Chen, "Nondestructive Analysis of Irradiated CANDU Fuels," Atomic Energy of Canada Limited report, AECL-6316, 1979.

J. C. Courtney, "A Handbook of Radiation Shielding Data," Louisiana State University report ANS/SD-76/14, 1976. 